\title{
PENGARUH BRAND EXPERIENCE, CUSTOMER SATISFACTION, DAN E-WOM TERHADAP PURCHASE INTENTION PENGGUNA APLIKASI HAPPY FRESH DI JAKARTA BARAT
}

\begin{abstract}
Ganesia dan Carunia Mulya Firdausy
Program Studi Manajemen Fakultas Ekonomi dan Bisnis Universitas Tarumanagara, Jakarta ganesia.115170240@stu.untar.ac.id caruniaf@pps.untar.ac.id

Abstract: This study aims to examine brand experience, customer satisfaction, and E-WOM on the purchase intention of Happy Fresh application users in West Jakarta. Method used to collect the sample was by using non-probability sampling method. The instrument to collect the data was by distributing a questionnaire, while method to analyze the data was by employing PLS-SEM. The results indicate that brand experience, customer satisfaction, and E-WOM positively influence the purchase intention of Happy Fresh application users in West Jakarta. Therefore, the Happy Fresh application must maintain the brand experience, customer satisfaction, and E-WOM to increase the purchase intention of Happy Fresh application users in West Jakarta.
\end{abstract}

Keywords: Brand Experience, Customer Satisfaction, Electronic Word of Mouth, Purchase Intention.

\begin{abstract}
Abstrak: Penelitian ini bertujuan untuk meneliti pengaruh brand experience, customer satisfaction, dan E-WOM terhadap purchase intenton pengguna aplikasi Happy Fresh di Jakarta Barat. Dalam penelitian ini, populasinya adalah pengguna aplikasi Happy Fresh di Jakarta Barat dan digunakan sampel sebanyak 100 sampel dengan menggunakan metode non probability sampling dengan teknik convenience sampling. Pengumpulan data dilakukan dengan menggunakan kuesioner dan data teserbut dianalisis dengan menggunakan PLS-SEM. Hasilnya ini menunjukkan bahwa brand experience, customer satisfaction, dan E-WOM memberikan pengaruh positif terhadap purchase intention pengguna aplikasi Happy Fresh di Jakarta Barat. Oleh karena itu, aplikasi Happy Fresh harus mempertahankan brand experience, customer satisfaction, dan E-WOM untuk meningkatkan purchase intention pengguna aplikasi Happy Fresh di Jakarta Barat.
\end{abstract}

Kata Kunci: Pengalaman Merek, Kepuasan Konsumen, e-WOM, Minat Beli.

\section{LATAR BELAKANG}

Dalam kondisi pandemi COVID-19, pemerintah menetapkan aturan dengan diadakannya Pembatasan Sosial Berskala Besar (PSBB) salah satunya di wilayah Jakarta. Dilansir pada Kompas.com dengan diadakannya PSBB membuat kegiatan masyarakat menjadi dibatasi seperti kegiatan belajar mengajar dan bekerja yang dilakukan di rumah secara online, kegiatan keagamaan dan kegiatan sosial budaya, serta kegiatan di tempat umum (https://www.kompas.com/). Hal tersebut tentunya membuat banyak kegiatan terganggu dan sulitnya memenuhi kebutuhan masyarakat.

Meski dalam keadaan PSBB, kebutuhan rumah tangga tetap dapat terpenuhi. Hal ini dipenuhi dengan menggunakan aplikasi Happy Fresh. Aplikasi Happy Fresh merupakan layanan belanja yang berbasis teknologi, sehingga masyarakat dapat berbelanja barang 
kebutuhannya tanpa harus pergi keluar (https://lifestyle.kompas.com/). Pada bulan Februari 2020, Happy Fresh menyatakan bahwa mereka memiliki 100.000 pengguna aktif setiap bulannya (https://www.teknogav.com/). Sejak pertengahan bulan Maret 2020, physical distancing sedang diberlakukan. Happy Fresh mengatakan bahwa transaksi yang dilakukan meningkat sebanyak 5 hingga 10 kali lipat dari transaksi biasanya (https://money.kompas.com/).

Walaupun aplikasi Happy Fresh mengalami peningkatan dari segi jumlah pengguna, tetapi ada juga pesaing lain dalam bidang yang sama seperti Honestbee, Sayurbox, Tanihub, Go-Mart, dan lainnya (https://www.popmama.com/). Tujuan dari penelitian ini adalah untuk mengetahui tingkat purchase intention aplikasi Happy Fresh selama masa pandemi dan dengan munculnya pesaing-pesaingnya. Dengan adanya hal ini, maka penelitian ini ditujukan untuk membahas faktor-faktor yang memengaruhi purchase intention dari layanan aplikasi Happy Fresh.

Penelitian terkait purchase intention terhadap aplikasi Happy Fresh masih belum banyak dilakukan. Namun, banyak dilakukan penelitian yang mengkaji faktor yang mempengaruhi purchase intention terhadap suatu produk. Penelitian ini juga dilakukan untuk melengkapi penelitian yang sudah ada sebelumnya.

Mbaye Fall Diallo et al (2015), misalnya, menyatakan bahwa brand experience dapat mempengaruhi purchase intention. Hal ini didasari dengan adanya pengalaman dari konsumen yang mempegaruhi penilaian tentang suatu produk ataupun jasa yang dapat mempengaruhi pembelian dalam bidang retail

Yingxia Cao et al (2017) mengatakan bahwa customer satisfaction mempengaruhi purchase intention secara signifikan. Hal ini dikarenakan dengan meningkatnya kepuasan, maka konsumen akan cenderung melakukan pembelian dan merekomendasikannya ke orang lain.

Sedangkan, Milad Farzin dan Majid Fattahi (2012) juga melakukan penelitian dan mengatakan bahwa E-WOM secara signifikan mempengaruhi purchase intention. Hal tersebut dikarenakan $E$-WOM biasanya ditampilkan pada profil penjual dalam platform online.

Berdasarkan penjelasan di atas, dapat disimpulkan bahwa penelitian ini dilakukan untuk meneliti pengaruh brand experience, customer satisfaction, dan E-WOM terhadap Purchase Intention Pengguna Aplikasi Happy Fresh di Jakarta Barat”.

\section{KAJIAN TEORI}

Teori yang digunakan dalam penelitian ini yakni Theory of planned behaviour. Teori ini merupakan teori hasil dari perkembangan theory of reasoned action. Teori ini menjelaskan mengenai niat individu untuk melakukan suatu perilaku. Teori ini memiliki tiga konsep yang idependen dalam menentukan niat, yaitu attitude toward the behaviour, subjective norm, dan perceived behavioural control (Ajzen, 1991).

Menurut Brakus, et al. (2009), brand experience adalah respon konsumen terhadap rangsangan terkait merek, seperti nama, logo, maskot, kemasan, komunikasi pemasaran, suasana toko dan lingkungan. Andianto dan Firdausy (2020:3) menyatakan bahwa "kepuasan adalah pemicu seorang konsumen untuk melakukan pembelian ulang, yang nantinya jika kepuasan itu terus menerus dirasakan oleh konsumen akan timbul rasa loyal terhadap produk tersebut." Hennig-Thurau et al (2004) mendefinisikan E-WOM sebagai pernyataan yang positif atau negatif yang dibuat oleh potensial, actual atau mantan konsumen tentang produk atau perusahaan yang disediakan untuk banyak orang atau lembaga melalui internet. Selanjutnya Wu et al. (2011) menyatakan purchase intention mengacu pada kemungkinan bahwa konsumen akan merencanakan atau membeli produk atau layanan tertentu di masa mendatang. Menurut 
Pengaruh brand experience terhadap purchase intention telah banyak diteliti. Diallo \& Siqueira Jr (2017) melakukan penelitian dibidang retail yang berada di Brazil dan Kolombia. Dalam penelitian tersebut didapatkan hasil bahwa brand experience memberikan hasil yang positif terhadap purchase intention. Pengaruh customer satisfaction terhadap purchase intention pernah dilakukan oleh Chiu \& Cho (2019) melakukan penelitian tentang pengalaman berbelanja secara online terhadap masyarakat China. Dari penelitian ini, didapatkan hasil bahwa customer satisfaction memberikan hasil yang positif terhadap purchase. Berikutnya penelitian yang dilakukan oleh Jalilvand \& Samiei (2012) dalam bidang industri automobile menunjukkan bahwa $E$-WOM memberikan dampak positif yang kuat terhadap purchase intention.

Pada penelitian ini, purchase intention dipengaruhi oleh brand experience, customer satisfaction, dan E-WOM. Morwitz and Schmittlein (1992) mengungkapkan "purchase intention relates to the likelihood that a consumer will buy a product", yang dapat diartikan sebagai purchase intention berkaitan dengan kemungkinan konsumen akan membeli suatu produk.

Berdasarkan uraian yang telah disebutkan di atas, didapatkan kerangka pemikiran sebagai berikut (Gambar 1).

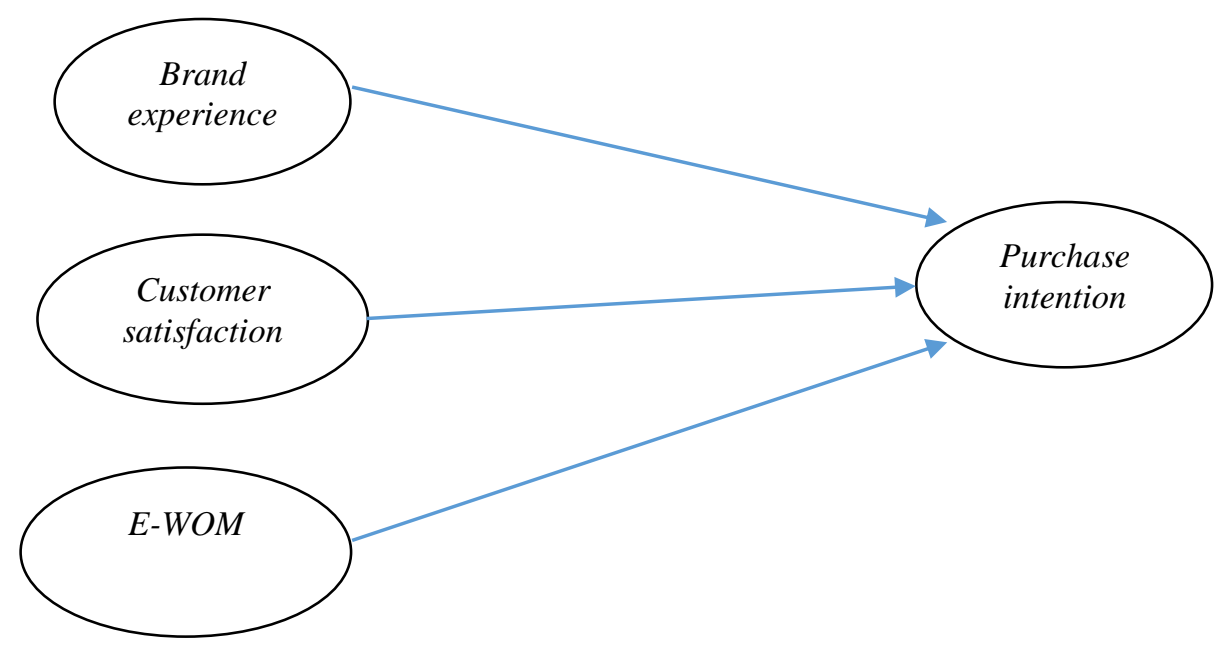

Gambar 1. Kerangka Pemikiran

Berdasarkan kerangka pemikiran di atas, didapatkan hipotesis sebagai berikut:

$\mathrm{H}_{1}$ : Brand experience memiliki pengaruh positif terhadap purchase intention pengguna aplikasi Happy Fresh di Jakarta Barat.

$\mathrm{H}_{2}$ : Customer satisfaction memiliki pengaruh positif terhadap purchase intention pengguna aplikasi Happy Fresh di Jakarta Barat.

$\mathrm{H}_{3}$ : E-WOM memiliki pengaruh positif terhadap purchase intention pengguna aplikasi Happy Fresh di Jakarta Barat.

\section{METODOLOGI}

Desain penelitian ini adalah desain penelitian deskriptif. Populasi penelitian ini adalah seluruh pengguna aplikasi Happy Fresh. Namun, dikarenakan jumlah dari populasi yang tidak dapat diketahui, maka digunakan sampel yaitu pengguna aplikasi Happy Fresh di Jakarta Barat. Teknik pemilihan sampel yang digunakan dalam penelitian ini adalah nonprobability sampling, yang dapat diartikan bahwa teknik pemilihan sampel ini tidak 
memberikan kesempatan atau peluang yang sama bagi setiap populasi untuk dipilih menjadi sampel. Dalam penelitian ini juga menggunakan teknik pengambilan sampel berupa teknik convenience sampling sampling, yaitu merupakan teknik pengambilan sampel dengan hanya beberapa anggota populasi yang bisa menjadi sampel karena terdapat beberapa kriteria yang dibutuhkan. Cara yang dilakukan adalah dengan menggunakan screening question.

Ukuran sampel penelitian ini berjumlah 100 responden yang berarti sudah layak untuk diteliti. Kriteria responden untuk penelitian ini adalah pengguna aplikasi Happy Fresh di Jakarta Barat. Instrumen yang digunakan dalam penelitian ini adalah dengan menggunakan instrumen kuesioner. Kuesioner disebarkan melalui online dengan menggunakan Google Form dan disebarkan kepada sampel melalui media sosial Line dan Whatsapp. Sumber responden Line dan Whatsapp berasal dari group chat teman dan keluarga. Cara ini digunakan agar dapat menghemat waktu dan biaya.

Metode analisis yang digunakan yakni analisis PLS-SEM dengan menggunakan software smartPLS. Skala yang digunakan dalam membobot indikator untuk semua variabel dalam penelitian ini menggunakan skala likert. Bentuk dari skala likert terdapat 1-5 skala, yaitu:

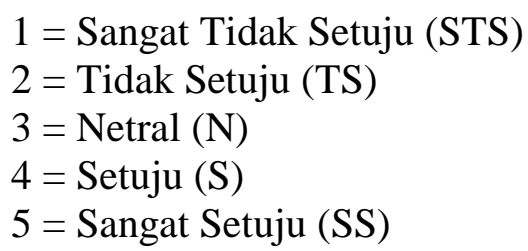

\section{HASIL ANALISIS DATA}

\section{Hasil Analisis Validitas}

Analisis validitas dengan teknik SEM dibagi menjadi validitas konvergen dan validitas diskriminan. Validitas konvergen dianggap valid apabila nilai AVE (average variance extracted) memiliki nilai lebih dari 0.5 (Hair et al., 2011) dan loading factor dari setiap variabel dengan nilai lebih dari 0.5 (Ghozali, 2012), jika memiliki nilai kurang dari 0.4, maka indikator tersebut dapat dihapus dari model penelitian (Henseler et al., 2009). Validitas diskriminan dilihat dari pendekatan Heteroit-Monotrait Ration (HTMT) yang dimana nilai HTMT yang baik adalah 0.85 , dan yang dapat diterima adalah kurang dari 0.9 (Henseler et al., 2015).

Tabel 1. Hasil Analisis Validitas Konvergen (AVE)

\begin{tabular}{l|c}
\hline \multicolumn{1}{c|}{ Variabel / Dimensi } & Average Variance Extracted \\
\hline Brand Experience & 0.748 \\
\hline Customer Satisfaction & 0.612 \\
\hline E-WOM & 0.631 \\
\hline Purchase Intention & 0.725 \\
\hline
\end{tabular}


Tabel 2. Hasil Analisis Validitas Diskriminan (Loading Factor)

\begin{tabular}{|c|c|c|c|c|}
\hline Indikator & Brand Experience & \begin{tabular}{|l|} 
Customer \\
Satisfaction
\end{tabular} & $E-W O M$ & Purchase Intention \\
\hline BE1 & 0.842 & & & \\
\hline $\mathrm{BE} 2$ & 0.899 & & & \\
\hline $\mathrm{BE} 3$ & 0.867 & & & \\
\hline BE4 & 0.876 & & & \\
\hline BE5 & 0.839 & & & \\
\hline CS1 & & 0.734 & & \\
\hline $\mathrm{CS} 2$ & & 0.729 & & \\
\hline CS3 & & 0.801 & & \\
\hline CS4 & & 0.812 & & \\
\hline CS5 & & 0.831 & & \\
\hline$\underline{\text { EWOM1 }}$ & & & 0.816 & \\
\hline EWOM2 & & & 0.812 & \\
\hline EWOM3 & & & 0.806 & \\
\hline EWOM4 & & & 0.800 & \\
\hline EWOM5 & & & 0.733 & \\
\hline PI1 & & & & 0.829 \\
\hline $\mathrm{PI} 2$ & & & & 0.830 \\
\hline PI3 & & & & 0.883 \\
\hline PI4 & & & & 0.859 \\
\hline PI5 & & & & 0.857 \\
\hline
\end{tabular}

Tabel 3. Hasil Analisis Validitas Diskriminan

\begin{tabular}{l|r|r|r|r}
\hline \multicolumn{1}{c|}{ Variabel } & Brand Experience & $\begin{array}{c}\text { Customer } \\
\text { Satisfaction }\end{array}$ & E-WOM & $\begin{array}{c}\text { Purchase } \\
\text { Intention }\end{array}$ \\
\hline Brand Experience & & & & \\
\hline Customer Satisfaction & 0.662 & & & \\
\hline E-WOM & 0.505 & 0.528 & & \\
\hline Purchase Intention & 0.830 & 0.792 & 0.662 & \\
\hline
\end{tabular}

Tabel 1 menunjukkan hasil uji validitas konvergen dan menunjukkan bahwa semua variabel memiliki nilai AVE lebih dari 0.5 yang dapat diartikan bahwa seluruh variabel dalam penelitian ini dapat digunakan sebagai variabel penelitian dan tabel 2 juga menunjukkan bahwa nilai loading factor pada setiap indikator memiliki nilai lebih dari 0.5. Tabel 3 juga menunjukkan hasil bahwa seluruh variabel memiliki nilai HTMT kurang dari 0.9. Oleh karena itu, dapat dikatakan bahwa seluruh variabel yang digunakan dalam penelitian ini dapat gunakan sebagi variabel penelitian. 


\section{Hasil Analisis Reliabilitas}

Uji reliabilitas dapat dilihat dari nilai composite reliability dari suatu konstruk. Indikator yang dapat diterima adalah lebih dari 0.7, namun nilai 0.6 masih dapat diterima. Tabel 4 menunjukkan bahwa seluruh nilai dari variabel dalam penelitian ini memiliki nilai composite reliability lebih dari 0.7 . Oleh karena itu, dapat dikatakan bahwa seluruh variabel dalam penelitian ini dinyatakan reliabel sehingga dapat digunakan sebagai instrumen penelitian.

Tabel 4. Hasil Analisis Konsistensi Internal

\begin{tabular}{l|c}
\hline \multicolumn{1}{c|}{ Variabel } & Composite Reliability \\
\hline Brand Experience & 0.937 \\
\hline Customer Satisfaction & 0.887 \\
\hline E-WOM & 0.895 \\
\hline Purchase Intention & 0.930 \\
\hline
\end{tabular}

\section{Hasil Analisis Multikoliniearitas}

Uji multikolinearitas dilihat dari nilai variance inflation factor (VIF). Nilai VIF sebesar atau diatas 5, menunjukkan adanya masalah kolinearitas kritis diantara indikator konstruksi yang diukur secara formal. Maka, penelitian ini memiliki ambang batas VIF tidak lebih dari 5. Tabel 5 menunjukkan hasil analisis multikolinearitas dalam penelitian ini memiliki hasil di bawah 5 .

Tabel 5. Hasil Analisis Multikolinearitas

\begin{tabular}{c|c}
\hline Variabel & Variance Inflation Factor (VIF) \\
\hline Brand Experience & 1.624 \\
\hline Customer Satisfaction & 1.642 \\
\hline E-WOM & 1.354 \\
\hline
\end{tabular}

\section{Hasil Analisis Koefisien Determinasi ( $\left.\mathbf{R}^{\mathbf{2}}\right)$}

Koefisien determinasi atau $r$-square dapat menjelaskan tentang pengaruh variable eksogen terhadap variable endogen. Nilai koefisien determinan dibagi menjadi 3 , yaitu 0.75 , 0.50 , dan 0.25 , yang masing-masing menjelaskan tingkat besar, sedang, atau kecil (Hair et al., 2019).

Tabel 6. Hasil Analisis Koefisien Determinasi $\left(\mathrm{R}^{2}\right)$

\begin{tabular}{c|c}
\hline Variabel & $\mathbf{R}^{\mathbf{2}}$ \\
\hline Purchase Intention & 0.713 \\
\hline
\end{tabular}

Tabel 6 menunjukkan hasil analisis dari $\mathrm{R}^{2}$ pada variabel purchase intention menunjukkan nilai sebesar 0.713 yang dapat diartikan juga sebesar $71.3 \%$ variabel purchase intention dipengaruhi oleh brand experience, customer satisfaction, dan E-WOM, yang berarti berada di tingkat sedang.

\section{Hasil Effect Size $\left(\mathbf{f}^{2}\right)$}

Effect size ditentukan melalui nilai model yang terbagi menjadi tiga, yaitu $0.02,0.15$, dan 0.35, yang menandakan efek model yang kecil, sedang, dan besar (Hair et al., 2014). 
Hipotesis dapat didukung jika path coefficients memiliki nilai yang berkisar antara -1 sampai +1 dan nilai $p$-value lebih kecil dari 0.05 .

Tabel 7. Hasil Analisis Effect Size $\left(\mathrm{f}^{2}\right)$

\begin{tabular}{l|c}
\hline & Purchase Intention \\
\hline Brand Experience & 0.476 \\
\hline Customer Satisfaction & 0.207 \\
\hline E-WOM & 0.139 \\
\hline
\end{tabular}

Tabel 7 menunjukkan hasil analisis dari $\mathrm{f}^{2}$, dapat disimpulkan bahwa pengaruh dari variabel brand experience terhadap purchase intention memiliki korelasi yang besar yaitu sebesar 0.476. Pengaruh pada variabel customer satisfaction terhadap purchase intention memiliki korelasi yang sedang yaitu sebesar 0.207. Sedangkan pengaruh pada variabel $E$ WOM terhadap purchase intention memiliki korelasi yang kecil yaitu hanya sebesar 0.139.

\section{Predictive Relevance}

Uji relevansi prediksi untuk mengukur seberapa baik nilai observasi serta estimasi parameter variable. Predictive relevance atau $Q$-Square dapat dikatakan baik apabila memiliki nilai lebih daripada 0 (Hair et al., 2011).

Tabel 8. Hasil Analisis Predictive Relevance $\left(\mathrm{Q}^{2}\right)$

\begin{tabular}{l|c}
\multicolumn{1}{c|}{ Variabel } & $\mathbf{Q}^{\mathbf{2}}$ \\
\hline Purchase Intention & 0.478 \\
\hline
\end{tabular}

Tabel 8 menunjukkan hasil analisis $\mathrm{Q}^{2}$ menyimpulkan bahwa hubungan dari variabel yang digunakan dalam penelitian ini dianggap relevan. Hal tersebut dikarenakan hasil dari $\mathrm{Q}^{2}$ menunjukkan nilai lebih dari 0 , yaitu 0.478 .

\section{Hasil Pengujian Hipotesis}

Pengujian hipotesis dilakukan untuk mengetahui adanya pengaruh secara positif atau tidak dalam penelitian ini. Pengujian ini dilakukan dengan menggunakan Bootstrapping. Pada penelitian ini, pengujian hipotesis dilakukan untuk mengetahui adanya hubungan brand experience, customer satisfaction, dan E-WOM terhadap purchase intention pengguna aplikasi Happy Fresh di Jakarta Barat.

Tabel 9. Hasil Uji Hipotesis

\begin{tabular}{|c|c|c|}
\hline Variabel & Nilai & Keterangan \\
\hline \multirow{2}{*}{$\begin{array}{l}\mathrm{H}_{1} \text { : Brand experience memiliki pengaruh positif } \\
\text { terhadap purchase intention pengguna aplikasi Happy } \\
\text { Fresh di Jakarta Barat. }\end{array}$} & $\beta=0.471$ & \multirow[b]{2}{*}{ Tidak Ditolak } \\
\hline & $p$-value $=0.000$ & \\
\hline \multirow{2}{*}{$\begin{array}{l}\mathrm{H}_{2}: \text { Customer satisfaction memiliki pengaruh positif } \\
\text { terhadap purchase intention pengguna aplikasi Happy } \\
\text { Fresh di Jakarta Barat. }\end{array}$} & $\beta=0.313$ & \multirow{2}{*}{ Tidak Ditolak } \\
\hline & $p$-value $=0.005$ & \\
\hline
\end{tabular}


$\mathrm{H}_{3}$ : E-WOM memiliki pengaruh positif terhadap purchase intention pengguna aplikasi Happy Fresh di Jakarta Barat.

$\mid$\begin{tabular}{l|}
$\beta=0.233$ \\
\hline$p$-value $=0.001$
\end{tabular}

Tidak Ditolak

Tabel 9 menunjukkan hasil pengujian hipotesis pada penelitian ini. Sehingga dapat disimpulkan bahwa variabel brand experience, customer satisfaction, dan E-WOM memberikan pengaruh yang positif dan signifikan terhadap purchase intention pengguna aplikasi Happy Fresh di Jakarta Barat.

\section{DISKUSI}

Berdasarkan hasil dari penelitian ini, dapat disimpulkan bahwa $\mathrm{H}_{1}$ tidak ditolak yang dapat diartikan bahwa brand experience berpengaruh secara positif dan signifikan terhadap purchase intention pada pelanggan Happy Fresh di Jakarta Barat. Data tersebut didukung juga oleh penelitian yang telah dilakukan oleh Lee \& Youn (2020) bahwa brand experience yang semakin baik maka akan meningkatkan purchase intention dari pengguna aplikasi Happy Fresh. Ini berarti pengalaman yang baik dari konsumen akan memberikan kesan yang baik bagi konsumen juga sehingga dapat meningkatkan minat untuk membeli.

Dari hipotesis kedua, didapatkan kesimpulan bahwa $\mathrm{H}_{2}$ tidak ditolak yang berarti customer satisfaction berpengaruh secara positif dan signifikan terhadap purchase intention. Hipotesis tersebut didukung juga oleh hasil penelitian yang telah dilakukan sebelumnya oleh Chiu \& Cho (2019) yang menyatakan bahwa semakin tinggi customer satisfaction maka akan meningkatkan purchase intention pengguna aplikasi Happy Fresh di Jakarta Barat. Semakin meningkatnya kepuasan konsumen maka semakin meningkat juga citra yang ditampilkan sehingga dapat meningkatkan minat untuk membeli.

Hasil dari uji hipotesis ketiga, diperoleh hasil bahwa E-WOM berpengaruh secara positif dan signifikan terhadap purchase intention. Hal ini didukung juga dengan penelitian yang telah dilakukan sebelumnya oleh Cendrawati dan Firdausy (2021) yang menyatakan bahwa adanya pengaruh positif dan signifikan dari E-WOM terhadap purchase intention. Sehingga dapat diartikan bahwa semakin positif E-WOM maka semakin meningkat juga purchase intention pengguna Happy Fresh di Jakarta Barat. Maka, dengan demikian citra dan ulasan yang positif juga akan meningkat sehingga dapat meningkatkan minat untuk membeli.

\section{KESIMPULAN} berikut:

Berdasarkan hasil dan pembahasan dari penelitian ini didapatkan kesimpulan sebagai

1. Brand experience berpengaruh secara positif dan signifikan terhadap purchase intention pada pengguna aplikasi Happy Fresh di Jakarta Barat.

2. Customer Satisfaction berpengaruh secara positif dan signifikan terhadap purchase intention pada pengguna aplikasi Happy Fresh di Jakarta Barat.

3. E-WOM berpengaruh secara positif dan signifikan terhadap purchase intention pada pengguna aplikasi Happy Fresh di Jakarta Barat.

\section{Saran}

Dalam penelitian berikutnya, disarankan untuk memperluas variabel yang ada, tidak hanya brand experience, customer satisfaction, dan E-WOM terhadap purchase intention. Hal tersebut didasarkan pada nilai $\mathrm{R}^{2}$ yaitu sebesar $71.3 \%$ yang dapat diartikan korelasi antar variabel sedang dan $28.7 \%$ yang dapat diteliti dengan variabel lainnya agar mendapatkan korelasi antar variabel yang lebih besar. 


\section{DAFTAR PUSTAKA}

Andianto, K., \& Firdausy, C. M. Pengaruh Perceived Value, Perceived Quality dan Customer Satisfaction terhadap Customer Loyalty Warunk Upnormal di Jakarta. Jurnal Manajerial Dan Kewirausahaan, 2(3), 758-764.

Brakus, J.J., Schmitt, B.H. and Zarantonello, L. (2009), "Brand experience: what is it? How is it measured? Does it affect loyalty?", Journal of marketing, Vol. 73, No. 3, pp. 52-68, http://dx.doi.org/10.1509/jmkg.73.3.52

Cao, Y., Ajjan, H., \& Hong, P. (2017). Post-purchase shipping and customer service experiences in online shopping and their impact on customer satisfaction: An empirical study with comparison. Asia Pacific Journal of Marketing and Logistics, 30(2), 400416. https://doi.org/10.1108/APJML-04-2017-0071

Cendrawati, W., \& Firdausy, C. M. (2021). Pengaruh Dukungan Selebriti, Kepercayaan, Dan Pemasaran Dari Mulut Ke Mulut Secara Elektronik Terhadap Niat Beli Pengguna Shopee Di Jakarta. Jurnal Manajerial Dan Kewirausahaan, 3(2), 559-568.

Chiu, W., \& Cho, H. (2019). E-Commerce brand. Asia Pacific Journal of Marketing and Logistics. https://doi.org/10.1108/apjml-10-2018-0403

Diallo, M. F., \& Siqueira Jr, J. R. (2017). How previous positive experiences with store brands affect purchase intention in emerging countries. International Marketing Review, 34(4), 536-558. https://doi.org/10.1108/imr-07-2014-0224

Farzin, M., \& Fattahi, M. (2018). eWOM through social networking sites and impact on purchase intention and brand image in Iran. Journal of Advances in Management Research, 15(2), 161-183. https://doi.org/10.1108/JAMR-05-2017-0062

Hair Jr, J. F., Sarstedt, M., Hopkins, L., \& Kuppelwieser, V. G. (2014). Partial least squares structural equation modeling (PLS-SEM): An emerging tool in business research. European Business Review, 26(2), 106- 121. https://doi.org/10.1108/EBR-10-2013$\underline{0128}$

Hair, J. F., Ringle, C. M., \& Sarstedt, M. (2011). PLS-SEM: Indeed a silver bullet. The Journal of Marketing Theory and Practice, 19(2), 139-151. https://doi.org/10.2753/MTP1069-6679190202

Hair, J. F., Risher, J. J., Sarstedt, M., \& Ringle, C. M. (2019). When to use and how to report the results of PLS-SEM. European Business Review, 31(1), 2- 24. https://doi.org/10.1108/EBR-11-2018-0203

Henni g-Thurau, T., Gwinner, K.P., Walsh, G. and Gremler, D.D. (2004), "Electronic wordof-mouth via customer opinion platform: what motivates consumers to articulate themselves on the internet", Journal of Interactive Marketing, Vol. 18 No. 1, pp. 38-52.

Henseler, J., Ringle, C. M., \& Sarstedt, M. (2015). A new criterion for assessing discriminant validity in variance-based structural equation modeling. Journal of the Academy of Marketing Science, 43(1), 115-135. https://doi.org/10.1007/s11747-014-0403-8

Lee, J. E., \& Youn, S. (2020). Luxury marketing in social media: The role of social distance in a craftsmanship video. Asia Pacific Journal of Marketing and Logistics. https://doi.org/10.1108/apjml-09-2019-0551

Morwitz, V.G. and Schmittlein, D. (1992), "Using segmentation to improve sales forecasts based on purchase intent: which 'intenders' actually buy?", Journal of Marketing Research, Vol. 29 No. 4, pp. 391-405

Sekaran, U., \& Bougie, R. (2013). Research methods for business: A skillbuilding approach (6th ed.). Wiley.

Wu, P.C.S., Yeh, G.Y.-Y. and Hsiao, C.-R. (2011), "The effect of store image and service quality on brand image and purchase intention for private label brands", Australasian Marketing Journal, Vol. 19 No. 1, pp. 30-39. 